This document is the accepted manuscript version of the following article:

Fu, Y. H., Zhang, X., Piao, S., Hao, F., Geng, X., Vitasse, Y., ... Janssens, I. A. (2019). Daylength helps temperate deciduous trees to leaf-out at the optimal time. Global Change Biology, 25(7), 2410-2418.

https://doi.org/10.1111/gcb.14633

\title{
Daylength helps temperate deciduous trees to leaf-out at the optimal time
}

Short title: Daylength guarantees leaf-out at right time

Authors: Yongshuo H. Fu ${ }^{1,2, *}$, Xuan Zhang ${ }^{1}$,Shilong Piao ${ }^{3,4,5}$, Fanghua Hao ${ }^{1}$, Xiaojun Geng ${ }^{1}$, Yann Vitasse $^{6}$, Constantin Zohner ${ }^{7}$, Josep Peñuelas ${ }^{8,9}$, Ivan A. Janssens ${ }^{2}$

\section{Affiliations:}

${ }^{1}$ Beijing Key Laboratory of Urban Hydrological Cycle and Sponge City Technology, College of water sciences, Beijing Normal University, Beijing, China

${ }^{2}$ Department of biology, University of Antwerp, Antwerp, Belgium

${ }^{3}$ Sino-French Institute for Earth System Science, College of Urban and Environmental Sciences, Peking University, Beijing 100871, China

${ }^{4}$ Key Laboratory of Alpine Ecology and Biodiversity, Institute of Tibetan Plateau Research, Chinese Academy of Sciences, Beijing 100085, China

${ }^{5}$ Center for Excellence in Tibetan Earth Science, Chinese Academy of Sciences, Beijing 100085, China

${ }^{6}$ Forest Dynamics Unit, Swiss Federal Institute for Forest, Snow and Landscape Research, WSL, Birmensdorf, Switzerland

${ }^{7}$ Institute of Integrative Biology, ETH Zurich (Swiss Federal Institute of Technology), 8092 Zurich, Switzerland

${ }^{8}$ CREAF, Cerdanyola del Vallès, Barcelona 08193, Catalonia, Spain

${ }^{9}$ CSIC, Global Ecology Unit CREAF-CSIC-UAB, Bellaterra, Barcelona 08193, Catalonia, Spain

Keywords: spring phenology, climate change, daylength, temperature response, deciduous trees 


\section{Abstract:}

Global warming has led to substantially earlier spring leaf-out in temperate-zone deciduous trees. The interactive effects of temperature and daylength underlying this warming response remain unclear, yet need to be accurately represented by Earth System models to improve projections of the carbon and energy balances of temperate forests and the associated feedbacks to the Earth's climate system. We studied the control of leaf-out by daylength and temperature using data from six tree species across 2377 European phenology observation sites (www.pep725.eu), each with at least 30 years of observations. We found that, in addition to- and independent of the known effect of chilling, daylength correlates negatively with the heat requirement for leaf-out in all studied species. In warm springs when leaf out is early, days are short and the heat requirement is higher than in an average spring, which mitigates the warming-induced advancement of leaf-out and protects the tree against precocious leaf-out and the associated risks of late frosts. In contrast, longer-than-average daylength (in cold springs when leaf-out is late) reduce the heat requirement for leafout, ensuring that trees do not leaf-out too late and miss out on large amounts of solar energy. These results provide the first large-scale empirical evidence of a widespread daylength effect on the temperature sensitivity of leaf-out phenology in temperate deciduous trees. 


\section{Introduction}

The timing of leaf-out co-determines the growth, reproductive success and competitiveness of temperate deciduous trees and thus strongly affects their fitness and distribution (Chuine, 2010). Global warming has led to substantially earlier spring leaf-out (Menzel et al., 2006, Parmesan \& Yohe, 2003, Peñuelas \& Filella, 2001), although this advance is declining (Fu et al., 2015). These changes in spring phenology may influence terrestrial ecosystem fluxes of carbon, water, nutrient and energy in a short term (Keenan et al., 2014, Myneni et al., 1997, Piao et al., 2017).

Mechanistic understanding of the leaf-out process is, however, far from complete (Chuine et al., 2010, Flynn \& Wolkovich, 2018, Körner \& Basler, 2010, Laube et al., 2014, Zohner et al., 2016), which challenges the projected impacts of climate change on ecosystems by dynamic global vegetation models (Richardson et al., 2012). A better understanding of the ecophysiological processes controlling leaf-out phenology is thus essential for improving our understanding of the responses of ecosystems to the ongoing climate change and the subsequent feedbacks to the climate system, as well as explaining the slow-down of the warming-induced advance in leaf out.

A species' optimal leaf-out date results from natural selection that optimizes the species' fitness under given environmental conditions, such as avoiding freezing damage (Lenz et al, 2016), ensuring flowering synchrony among species (Elzinga, Atlan and Biere, 2007; Zohner, Mo \& Renner, 2018) and maximizing the length of the remaining season for light and nutrient resources (competition with other trees) as 
well as for tissues maturation (Körner et al, 2016). In temperate and boreal regions, temperature, including both cold winter temperatures (chilling requirement) and warm spring temperatures (heat requirement), and daylength interact to realize leaf out around the optimal date (Flynn \& Wolkovich, 2018, Körner \& Basler, 2010). Chilling accumulates over autumn and winter, and when the accumulated chilling exceeds the chilling requirement, endodormancy (the first stage of dormancy (Lang, 1987)) is broken and buds enter the second dormancy stage: ecodormancy (Chuine \& Régnière, 2017, Hänninen, 2016). During ecodormancy, meristem cells begin to grow, a process that is accelerated by warm temperatures and a gradually increasing daylength (Hänninen, 2016). Inter-annual variation of these three environmental drivers is strongly correlated (e.g. a warm winter reduces chilling and increases heat supply, and the earlier leaf-out associates with short daylength). As a result, the direct effect of daylength on spring phenology and its eventual interactions with chilling and the heat requirement remain unclear and highly debated (Chuine et al., 2010, Flynn \& Wolkovich, 2018, Körner \& Basler, 2010, Laube et al., 2014, Zohner et al., 2016). In this study, based on a large set of in situ phenology observations across Europe (www.pep725.eu), we propose a framework to unravel the effect of daylength on leafout phenology of temperate-zone deciduous trees and test the hypothesis that daylength affects the leaf-out process by altering the heat requirement at any given chilling accumulation. 
We start by assuming that trees are characterized by an optimal, climate-dependent, daylength (Figure. 1). Occasional late frost events give a competitive disadvantage to individuals that leaf-out earlier than the species' optimal daylength, while reduced light harvesting gives a competitive disadvantage to individuals that leaf-out later than the optimum period. As such, an optimal date of leaf-out exists for a given species, determined by a trade-off between maximizing annual carbon and nutrient uptake to ensure competitive advantage by lengthening the duration of the ground cover period (earlier leaf out is preferred) and reducing the risk of late frost damage after leaf out (later leaf out gives more security and is thus preferred (Allstadt et al., 2015, Liu et al., 2018) (Figure. 1a). In the long term, carbon assimilation and competitiveness are determined by the lowest of these two cost functions, and the optimal leaf out date occurs where the minimum cost yields the highest carbon assimilation and competitiveness. Experimental studies have revealed a nonlinear relation between accumulated chilling and the heat required for leaves to flush (typically quantified as growing degree day units, GDD) (Figure. 1b). Daylength is hypothesized to act as a cue controlling the sensitivity of meristem cell growth to warm temperatures, thereby altering the apparent relationship between chilling and GDD requirement. Their nonlinear relation becomes steeper when days are shorter than optimal (short daylength, Figure. 1c) and less steep when days are longer than optimal (long daylength, Figure. 1d). 
110 Two substantially different impacts of sub-optimal daylength on leaf-out date are thus

111 theoretically possible: (i) Shorter than optimal daylength reduces the temperature

112 sensitivity (increases the GDD requirement), thereby avoiding precocious leaf-out that

113 would increase the risk of frost damage, (i.e. the short daylength effect, Figure. 1c).

114 (ii) Longer than optimal daylength increases the temperature sensitivity (reduces the

115 GDD requirement), effectively avoiding belated leaf-out at a time when solar

116 radiation is high and thus ideal for photosynthesis (i.e. the long daylength effect,

117 Figure. 1d).

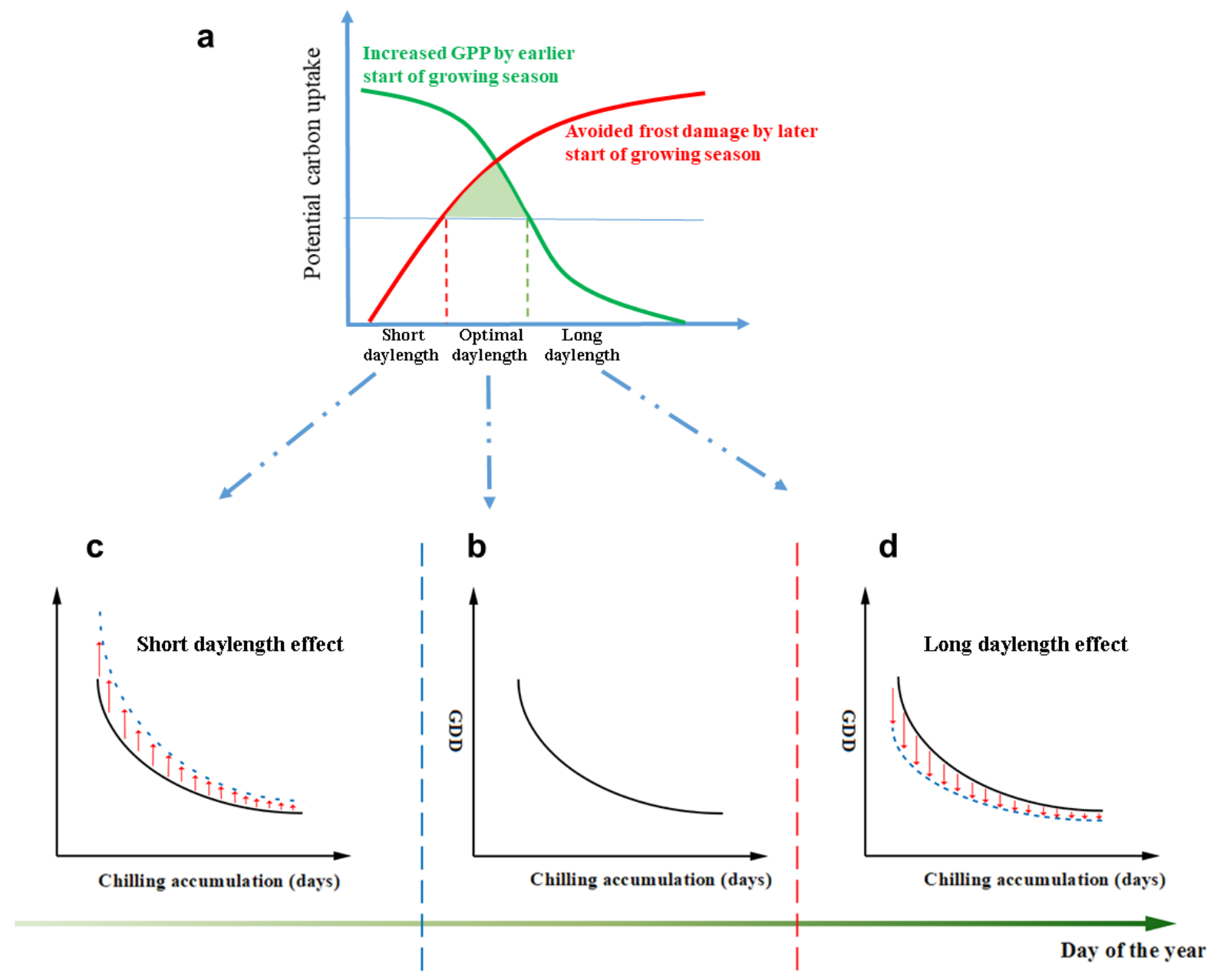


118 Figure 1. (a) Conceptual scheme depicting why an optimal daylength for tree leaf-out 119 exists within which the competitiveness of a species is maximized and how this is 120 realized. Tree competitiveness is increased by earlier start of the growing season,

121 which maximizes annual carbon and nutrient uptake and reduces that of the 122 neighbors, but is subject to a trade-off with avoiding the risk of late frost-induced 123 damage for which a later start of growing season is preferred. The green filled area represents the leaf-out period that ensures the most secure, high competitiveness and 125 carbon uptake. This study provides evidence that the spring leaf-out process requires 126 less warm temperatures (lower heat requirement; GDD), and thus becomes more 127 temperature responsive, as daylength increases. As such, daylength aids in constraining leaf-out within the optimal period in both cold and warm springs. (b) In very warm springs, when leaf-out is early, trees minimize the advance of leaf-out because their temperature sensitivity is low under short daylength. This is reflected in an increased GDD requirement and results in trees being protected against late frost events, i.e. the "short daylength effect": (c) Under optimal daylength the GDD required for leaf-out is mainly determined by the chilling accumulated during endodormancy; (d) In very cold springs, when leaf-out is late, trees minimize the

135 delay of leaf-out because their temperature sensitivity becomes greater under 136 increasing daylength. This high temperature sensitivity is reflected in the reduced GDD requirement, and protects trees against leafing-out too late, i.e. the "long daylength effect". 
These two postulated consequences of daylength impacts have not been strongly

141 supported by empirical evidence. The short daylength effect in early spring, to our

142 knowledge, has not yet been empirically documented, whereas the long daylength

143 effect in late spring has been experimentally evidenced in earlier studies, albeit only

144 on cut twigs or saplings (Flynn \& Wolkovich, 2018, Körner \& Basler, 2010, Laube et

145 al., 2014, Malyshev et al., 2018) and not yet on mature trees. We therefore set out to

146 show the consequences of both a short and a long daylength on spring leaf-out of

147 mature trees of temperate deciduous tree species, to assess how widespread these two

148 effects are across these species, to quantify the sensitivities of the GDD requirement

149 to sub- and supra-optimal daylength and, last, to determine the relative importance of

150 chilling and daylength as controls of the leaf-out process.

Materials and methods

153 We tested the daylength effect on mature trees using data from 2377 sites of the

154 European phenological network (http://www.pep725.eu/) (Templ et al., 2018). The date

155 of leaf-out had been recorded at each site for at least 30 years between 1950 to 2016,

156 but in most cases observations were available for many more years. Six deciduous tree 157 species were selected (for which sufficient observational data were available): Fagus 158 sylvatica (beech), Aesculus hippocastanum (horse chestnut), Betula pendula (birch), 159 Fraxinus excelsior (ash), Quercus robur (oak) and Tilia cordata (lime). In total 509,284 160 individual observations from 12348 site-species combinations at 2377 sites were used. 161 The sites mainly occurred in moderate climates in Central Europe (Supplementary 
Figure 1 and 2). The leaf-out dates were defined based on the BBCH code (Biologische Bundesanstalt, Bundessortenamt und Chemische Industrie, $\mathrm{BBCH}=11$, first visible leaf stalk) (Templ et al., 2018). We first determined the preseason length for each species at each site as the period before leaf-out for which the partial correlation coefficient between leaf-out and air temperature was highest (Fu et al, 2015). Using this optimal preseason, we then calculated the GDD requirement for each species at each site and in each year. We defined the GDD requirement as an integration of daily mean temperature $(T t)$ above a temperature threshold $(T t h)$ throughout the preseason with the mean leaf-out dates as the end:

$$
G D D=T t-T t h, \quad \text { if } T t>T t h
$$

where $T t h$ is the threshold temperature for GDD accumulation and $T t$ is the mean daily temperature. We used a threshold $T$ th of $5{ }^{\circ} \mathrm{C}$. We also tested a temperature threshold of $0{ }^{\circ} \mathrm{C}$, which produced very similar results. To best the robustness of the results, we further calculated the GDD from the $1^{\text {st }}$ December to the date of leaf-out for each species at each site, and found very similar results (Supplementary Figure 3). We therefore only report results using the threshold of $5{ }^{\circ} \mathrm{C}$ and the preseason Chilling occurs at low, yet non-freezing temperatures and the number of days with mean temperature between 0 and $5^{\circ} \mathrm{C}$ was suggested as a good proxy for chilling accumulation, although inter-species variation in the chilling efficiency of different temperatures is probably high. Chilling requirement is a physiological parameter that corresponds to the amount of chilling needed to break endodormancy and enter the ecodormancy. In the present study, chilling was calculated as the number of days (CD) 
when daily temperature was between 0 and $5{ }^{\circ} \mathrm{C}$ from 1 September in the previous year until the day of leaf-out. We also tested another approach, using $0^{\circ} \mathrm{C}$ and $10{ }^{\circ} \mathrm{C}$ as temperature thresholds counting all days with mean temperatures between these thresholds, which produced very similar results. Similar results were also obtained when below-freezing temperatures were included, calculating as the number of days when daily temperature below $5{ }^{\circ} \mathrm{C}$ (Supplementary Figure 4) or $7{ }^{\circ} \mathrm{C}$ (Supplementary Figure 5), and similar results were obtained. We therefore only report the results based on the chilling accumulation using the $0{ }^{\circ} \mathrm{C}-5^{\circ} \mathrm{C}$ temperature range.

Daylength at the day of leaf-out (DL) was calculated as a function of latitude and DOY:

$$
\mathrm{DL}=24-\frac{24}{\pi} \cos ^{-1}\left[\frac{\sin \frac{0.8333 \pi}{180}+\sin \frac{\mathrm{L} \pi}{180} \sin \varphi}{\cos \frac{\mathrm{L} \pi}{180} * \cos \varphi}\right]
$$

$$
\begin{gathered}
\varphi=\sin ^{-1}\left(0.29795^{*} \cos \theta\right) \\
\theta=0.2163108+2 * \tan ^{-1}(0.9671396 * \tan (0.0086 *(\mathrm{DOY}-186)))
\end{gathered}
$$

where $L$ is the latitude of the phenological site.

The daily mean air temperature at each site was derived from a gridded climatic data set of daily mean temperature at $0.25^{\circ}$ spatial resolution (approximately $25 \mathrm{~km}$, ERAWATCH) (Fu et al., 2014).

\section{The sensitivity of GDD requirement to chilling and daylength}


We calculated cumulative chilling, the GDD requirement and daylength at the day of leaf-out for each year at each site. For each individual tree, we divided the data into

204 four subsets according to chilling accumulation, i.e. case 1: lowest chilling accumulation: $\mathrm{CD}<\mathrm{CDmean}-1$ standard deviation of $\mathrm{CD}$ (CDsd); case 2: low chilling accumulation: CDmean-CDsd $<$ CD $<$ CDmean; case 3: high chilling accumulation: CDmean $<\mathrm{CD}<\mathrm{CDmean}+\mathrm{CDsd}$, and case 4: highest chilling accumulation: $\mathrm{CD}>\mathrm{CDmean}+\mathrm{CDsd}$. Within each $\mathrm{CD}$ subset, we subsequently calculated the GDD requirement for three daylength conditions, i.e. leaf-out under short-daylength conditions (DL < DLmean - 0.75 DLsd), under long-daylength conditions (DL > DLmean + 0.75 DLsd) and under average-daylength conditions (DLmean - 0.5 DLsd < DL < DLmean + 0.5 DLsd). The differences in mean GDD requirement for leaf-out among the DL groups were tested using independent t-tests for each chilling case and each species. Furthermore, we calculated the daylength sensitivity of GDD as the slope of the linear regression between GDD and DL, and then the average of the four daylength sensitivities was determined for each species at each site. Using similar methodology, we divided the data into four subsets according to DL for each individual tree, i.e. case 1: shortest daylength: DL < DLmean - DLsd; case 2: short daylength: DLmean - DLsd < DL < DLmean; case 3: long daylength: DLmean $<$ DL $<$ DLmean + DLsd, and case 4: longest daylength: DL $>$ DLmean + DLsd, and then calculated the chilling sensitivity of GDD for each species at each site. To compare the relative importance of chilling versus that of daylength as 
determinants of the GDD requirement for leaf-out, we first normalized the daylength and chilling sensitivity, respectively, using a min-max normalization for each species:

$$
\mathrm{Si}=\frac{(\mathrm{Si}-\mathrm{Smin})}{(\operatorname{Smax}-\mathrm{Smin})}
$$

Where Si is the daylength or chilling sensitivity at site i, Smin and Smax are the minimum and maximum observed values of the daylength - or chilling sensitivity across all trees of that species. Then, the mean and standard deviation of all normalized sensitivities was calculated for each species. Histograms were used to show the distribution of sensitivities across all trees for each species.

\section{Results and discussion}

In agreement with a multitude of previous studies (Cannell \& Smith, 1983, Fu et al., 2016, Laube et al., 2014), we found that all studied tree species showed lower GDD requirement under higher chilling conditions (Figure 2 and Supplementary Table 1). Interestingly, we also observed that in all six species and within each CD group, the GDD requirement for leaf-out was statistically significantly higher under short- than average-daylength conditions, and significantly lower under long- than averagedaylength conditions (using paired $t$ test, $P<0.001$, Figure 2, and Supplementary Figure 6 and Supplementary Table 2 as an example at high chilling accumulation). Contrasting results of the photoperiod effect were reported in experimental studies (Heide 1993; Laube et al, 2014). However, almost all of these studies are based on cuttings or saplings in manipulative experiments, and using constant day length rather natural continuous changes in day length (e.g. Zohner et al, 2016; Laube et al., 
2014)., and young trees often behave opportunistically and exhibit earlier leaf-out than mature trees of the same species. Using trees of different ontogenetic stages might thus explain part of the differences among previous studies. In the present study, we selected six species that belong to five families (Fagaceae, Betulaceae, Malaceae, Sapindaceae, Oleaceae), some of which phylogenetically quite distinct (Supplementary Figure 4). Because every tested species (all six species for which sufficient observations were available) exhibited very similar daylength responses, we postulate the widespread existence of a daylength effect among temperate zone deciduous tree species, at least among European temperate-zone tree species. In line with our findings, a recent study found consistent daylength effects on leaf-out phenology exists across 28 woody species in a North American temperate forest (Flynn \& Wolkovich, 2018).

For each individual tree, we calculated the sensitivity of the GDD requirement for leaf-out to changes in daylength. On average across all species and averaged over four

259 different chilling intensities, compared to the GDD requirement under average 260 daylength conditions, each one-hour decrease in daylength (comparable to the 261 observed inter-annual range) increased GDD by $37^{\circ} \mathrm{C}$-days, i.e. by $26 \%$

262 (Supplementary Figure 8a and b), while a 1-h increase in daylength decreased the 263 GDD requirement by $31^{\circ} \mathrm{C}$-days, i.e. by $22 \%$ (Supplementary Figures $8 \mathrm{a}$ and b). We 264 further compared the relative sensitivity of the GDD requirement for leaf-out to 265 chilling and daylength (comparing the GDD response to one standard deviation of the 

sensitivity differences among the six study species (Figure. 3).
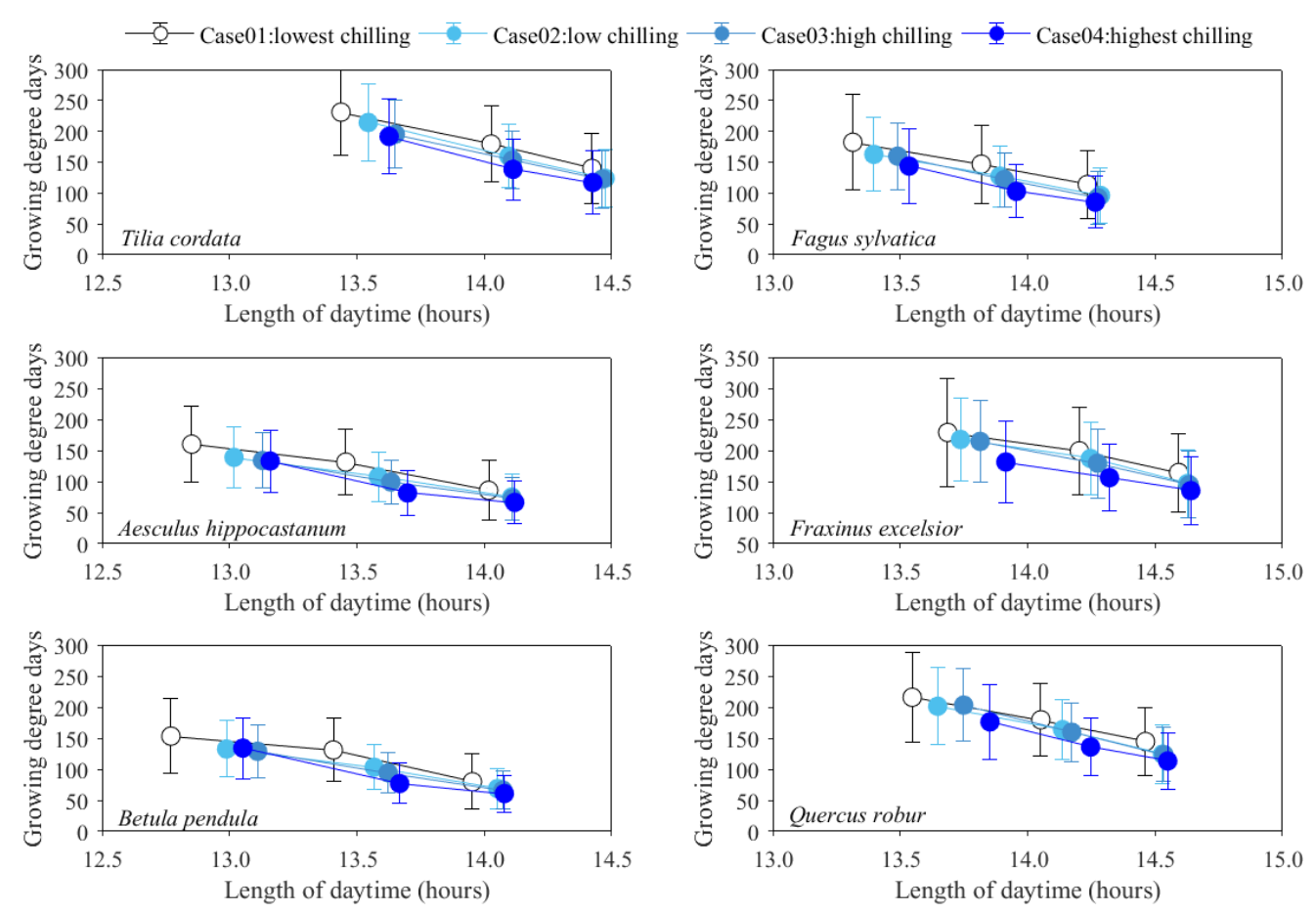

Figure 2. Dependence of GDD requirement of leaf-out on daylength under constant

269 chilling conditions for six tree species. Dependencies are shown for four different

270 chilling intensities (see Methods).

272 In detail, sensitivity to daylength was larger than the sensitivity to chilling in four out 273 of six species: Betula pendula, Aesculus hippocastanum, Tilia cordata and Fraxinus

274 excelsior, while no difference was detected in Quercus robur. Fagus sylvatica also

275 exhibited a pronounced sensitivity to daylength, but its sensitivity to chilling was even 276 greater (Figure. 3). Fagus sylvatica is indeed known as a highly chilling-sensitive 277 species (Kramer, 1994, Malyshev et al., 2018). Our findings thus confirm that 278 daylength is an important co-regulator of leaf-out in mature temperate deciduous trees 
279 (Flynn \& Wolkovich, 2018, Körner \& Basler, 2010), and further suggest that 280 daylength likely affects the leaf-out process indirectly by altering the non-linear 281 relationship between chilling and GDD requirement. These results also support the 282 hypothesis that the shorter daylength due to earlier leaf-out in spring contributes to the 283 declining apparent temperature sensitivity of leaf-out in European temperate 284 deciduous trees (Fu et al. 2015). These mechanisms are conceptualized in Figure. 4. 285 With climate warming, the GDD requirement increases due to reduced chilling, but 286 GDD supply increases more (Figure. 4, panel a). As a result, GDD supply equals 287 GDD requirement earlier in the year (visualized as an excess GDD supply in Figure 4, 288 panel a), which drives earlier leaf-out. The associated shorter daylength, however, 289 further increases the GDD requirement and thereby restricts the advance of leaf-out 290 (Figure. 4, panel b) and reduces the temperature sensitivity of leaf-out with climate 291 warming. 

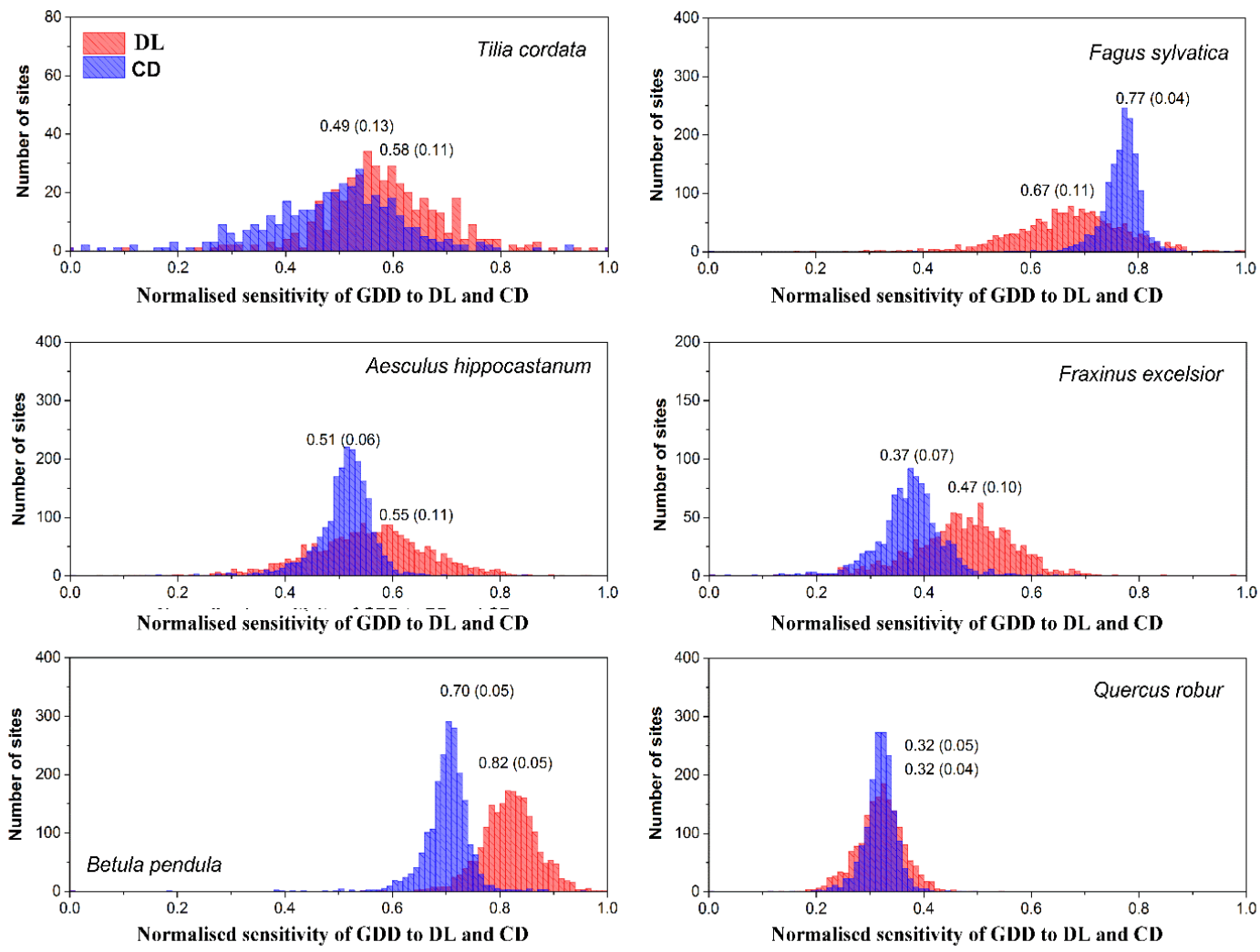

292 Figure 3. Histograms of the Growing Degree Day (GDD) sensitivity to changes in

293 daylength (DL, in red) and in chilling (CD, in blue) across all individual trees of six

294 deciduous tree species. Sensitivity was calculated as the change in GDD per one

295 standard deviation in the observed DL and CD, respectively, and is therefore coined

296 'normalized sensitivity'. mean sensitivities and standard deviations (in brackets) are

297 provided. 


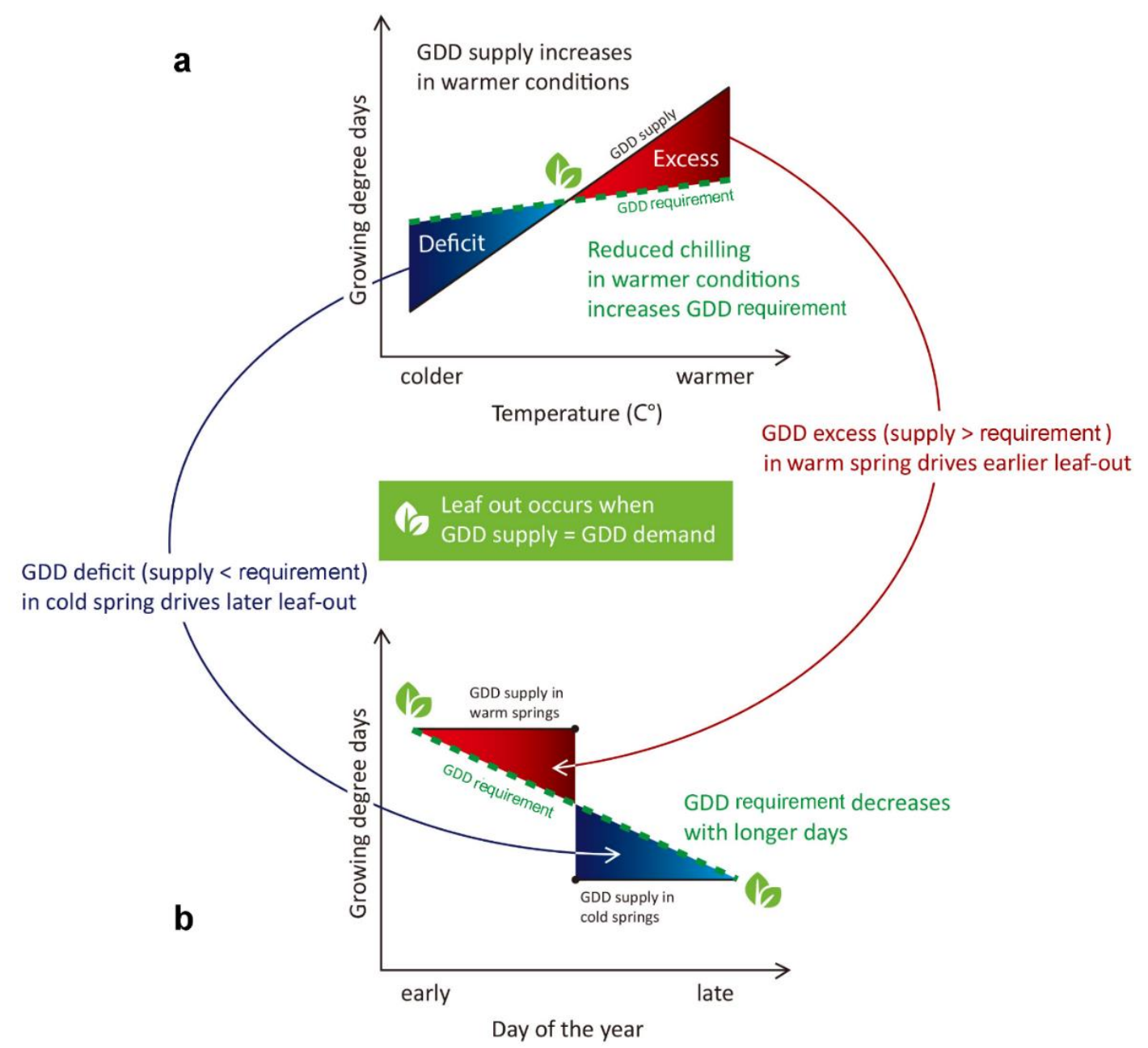

298 Figure. 4. Conceptual scheme summarizing how daylength helps deciduous trees to

299 leaf-out within or close to the optimal period. (a) Leaf-out occurs when the supply of

300 warm temperatures (GDD supply: accumulated daily growing degree days, GDD;

301 black line) equals the GDD requirement (physiological parameter to trigger leaf-out).

302 Note that the $X$ axes indicate the climate from cold to warm spring. The more chilling

303 is accumulated, the lower the GDD requirement (green dashed line; for simplicity

304 reasons we here assume a linear relation). In cold springs, the deficit in GDD supply

305 drives a delay in leaf-out date (blue areas in panels $\boldsymbol{a}$ and $\boldsymbol{b}$ ). (b) The associated

306 increasing daylength, however, increases the temperature sensitivity and thereby

307 causes a decline in the GDD requirement, with leaf-out occurring when GDD supply 
equals the declining GDD requirement. In contrast, in warm springs (red areas in panels $\boldsymbol{a}$ and $\boldsymbol{b}$ ), GDD supply typically exceeds the chilling-induced GDD requirement earlier in the year, but the short daylength earlier in spring induces a low temperature sensitivity and thereby an increased GDD requirement, which minimizes the warming-induced advance of leaf-out. Note that the X axes indicate the leaf-out timing from early to late.

Daylength thus acts as an environmental cue, counteracting the advancing impact of global warming, and helping trees to leaf-out close to their optimal date. As daylength increases from early to late spring, we observed that the GDD requirement also decreases under similar chilling conditions. Similar responses, supporting our findings, were previously reported in experimental studies using cuttings, although the daylength difference among treatments was very large in these studies (Zohner et al., 2016). There are also other studies that reported a decreased photoperiod effect with increasing chilling accumulation (Laube et al, 2014; Hänninen 2016), which may be because the increasing chilling ensures leaf out at the optimal daylength, when the photoperiod effect is minimal. We observed that the GDD requirement decreases consistently from very short to very long daylength, suggesting that one single physiological mechanism may suffice to explain the protective effect of daylength against both early as well as late leaf-out. We speculate that daylength directly impacts on the temperature sensitivity of cell development to warming. By keeping the calculation of GDD constant with daylength, the increase in temperature 
sensitivity with increasing daylength is mathematically translated into a reduced GDD

requirement. However, we acknowledge that the heat signal required by the meristems to initiate leaf-out may not be directly altered by daylength, but that the heat signal reception may become more efficient with increasing daylength. Our data, unfortunately, do not allow unraveling the underlying physiological mechanism.

We further speculate that the daylength control over the GDD requirement depends on the start date of the ecodormancy phase relative to the date when optimal daylength thresholds are reached or passed. When ecodormancy begins late relative to the optimum daylength thresholds, the temperature sensitivity of cell development is elevated, resulting in reduced GDD requirement to force leaf-out. In contrast, when ecodormancy starts earlier than the target daylength threshold, the temperature sensitivity of cell development may remain low, but not zero, until the date when the optimal daylength threshold is passed. The starting date of ecodormancy, however, cannot easily be determined empirically and is therefore typically ignored in phenology studies, explaining why the relation between daylength and the start of ecodormancy remains poorly understood (Chuine et al., 2016), despite their importance for pushing the field beyond the state of the art (Hänninen, 2016). To our knowledge, neither the start date of ecodormancy, i.e. the start date of GDD accumulation, nor the optimal daylength thresholds have been well studied (but see Chuine et al, 2016). As long as dormancy remains poorly understood, also the estimations of chilling and forcing units remain uncertain. For example, the duration 
of the chilling accumulation period and the start date of the heat accumulation period, as well as their interactions are still unclear. Similarly, the optimal temperature ranges for chilling accumulation and the temperature threshold above which GDD's start to accumulate, as well as the length of GDD accumulation are poorly understood.

Different assumptions can, however, lead to contrasting and sometimes illogical results. For example, an increased GDD requirement is obtained when leaf out is very late and the GDD is calculated over a fixed number of days prior to leaf out (see Supplementary Figure 9). Studies focusing on ecophysiological experiments are thus urgently needed to fully understand spring phenology and enable the development of reliable phenology synthesis studies and -models (Chuine \& Régnière, 2017, Hänninen et al., 2019).

Climate warming-induced spring phenology advances substantially alter regional and global biogeochemical cycles and climate systems (Forzieri et al., 2017, Myneni et al., 1997, Peñuelas \& Filella, 2009). However, as the daylength effect reduces the temperature sensitivity of leaf-out in warmer years, slowing down the advancing rate of leaf-out, it thereby also reduces the warming-induced extension of ground cover, and the carbon uptake, evapotranspiration and albedo. This study found that all investigated temperate-zone deciduous tree species (the six species for which sufficient observational data were available) use daylength as a signal to help ensuring that leaf-out occurs close to a species-dependent optimal time of the year, by 
373 increasing the GDD requirement for leaf-out when daylength is too short, and

374 reducing the GDD requirement as daylength becomes too long.

375

\section{References}

Allstadt AJ, Vavrus SJ, Heglund PJ, Pidgeon AM, Thogmartin WE, Radeloff VC (2015) Spring plant phenology and false springs in the conterminous US during the 21st century. Environmental Research Letters, 10, 104008.

Cannell M, Smith R (1983) Thermal time, chill days and prediction of budburst in Picea sitchensis. Journal of Applied Ecology, 951-963.

Chuine I (2010) Why does phenology drive species distribution? Philosophical Transactions of the Royal Society B: Biological Sciences, 365, 3149-3160.

Chuine I, Bonhomme M, Legave JM, García De Cortázar-Atauri I, Charrier G, Lacointe A, Amé glio $T$ (2016) Can phenological models predict tree phenology accurately in the future? The unrevealed hurdle of endodormancy break. Global Change Biology, 22, 3444-3460.

Chuine I, Morin X, Bugmann H (2010) Warming, Photoperiods, and Tree Phenology. Science, 329, 277-278.

Chuine I, Régnière J (2017) Process-Based Models of Phenology for Plants and Animals. Annual Review of Ecology, Evolution, and Systematics, 48, 159-182.

Elzinga JA, Atlan A, Biere A, Gigord L, Weis AE, Bernasconi G. 2007. Time after time: flowering phenology and biotic interactions. Trends in Ecology and Evolution, 22, 432-439.

Flynn DFB, Wolkovich EM (2018) Temperature and photoperiod drive spring phenology across all species in a temperate forest community. New Phytologist, 219, 13531362.

Forzieri G, Alkama R, Miralles DG, Cescatti A (2017) Satellites reveal contrasting responses of regional climate to the widespread greening of Earth. Science, 356, 1180-1184.

Fu YH, Campioli M, Vitasse Y et al. (2014) Variation in leaf flushing date influences autumnal senescence and next year's flushing date in two temperate tree species. Proceedings of the National Academy of Sciences of the United States of America, 111, 73557360 .

Fu YH, Liu Y, De Boeck HJ et al. (2016) Three times greater weight of daytime than of nighttime temperature on leaf unfolding phenology in temperate trees. New Phytologist, 212, 590-597. 
Fu YH, Zhao HF, Piao SL et al. (2015) Declining global warming effects on the phenology of spring leaf unfolding. Nature, 526, 104-107.

Hänninen H (2016) Boreal and temperate trees in a changing climate. Netherlands, Springer Business Media, Dordrecht.

Hänninen H, Kramer K, Tanino K, Zhang R, Wu J, Fu YH (2019) Experiments are necessary in process-based tree phenology modelling. Trends in Plant Science, 24, 199-209.

Heide O.M. (1993) Day length and thermal time responses of budburst during dormancy release in some northern deciduous trees, Physiologia plantarum, 88, 531-540.

Keenan TF, Gray J, Friedl MA et al. (2014) Net carbon uptake has increased through warming-induced changes in temperate forest phenology. Nature Climate Change, 4 , 598.

Körner C, Basler D (2010) Phenology Under Global Warming. Science, 327, 1461-1462.

Körner C, Basler D, Hoch G, Kollas C, Lenz A, Randin CF, Vitasse Y, Zimmermann NE (2016) Where, why and how? Explaining the low-temperature range limits of temperate tree species. Journal of Ecology, 104, 1076-1088

Kramer K (1994) Selecting a model to predict the onset of growth of Fagus sylvatica. Journal of Applied Ecology, 31, 172-181.

Lang GA (1987) Dormancy: a new universal terminology. HortScience, 22, 817-820.

Laube J, Sparks TH, Estrella N, Höfler J, Ankerst DP, Menzel A (2014) Chilling outweighs photoperiod in preventing precocious spring development. Global Change Biology, 20, 170-182.

Lenz A, Hoch G, Körner C, Vitasse Y (2016) Convergence of leaf-out towards minimum risk of freezing damage in temperate trees, Functional Ecology, 9, 1480-1490.

Liu Q, Piao S, Janssens IA et al. (2018) Extension of the growing season increases vegetation exposure to frost. Nature Communications, 9, 426.

Malyshev AV, Henry HA, Bolte A, Khan MaA, Kreyling J (2018) Temporal photoperiod sensitivity and forcing requirements for budburst in temperate tree seedlings. Agricultural and Forest Meteorology, 248, 82-90.

Menzel A, Sparks TH, Estrella N et al. (2006) European phenological response to climate change matches the warming pattern. Global Change Biology, 12, 1969-1976.

Myneni RB, Keeling C, Tucker CJ, Asrar G, Nemani RR (1997) Increased plant growth in the northern high latitudes from 1981 to 1991. Nature, 386, 698.

Parmesan C, Yohe G (2003) A globally coherent fingerprint of climate change impacts across natural systems. Nature, 421, 37-42.

Peñuelas J, Filella I (2001) Responses to a warming world. Science, 294, 793-795. 
Peñuelas J, Filella I (2009) Phenology feedbacks on climate change. Science, 324, 887-888.

Piao S, Liu Z, Wang T et al. (2017) Weakening temperature control on the interannual variations of spring carbon uptake across northern lands. Nature Climate Change, 7, 359.

Richardson AD, Anderson RS, Arain MA et al. (2012) Terrestrial biosphere models need better representation of vegetation phenology: results from the North American Carbon Program Site Synthesis. Global Change Biology, 18, 566-584.

Templ B, Koch E, Bolmgren K, Ungersbock M, Paul A, Scheifinger H (2018) Pan European Phenological database (PEP725): a single point of access for European data. International journal of biometeorology, 62, 1-5.

Vitasse Y, Basler D (2013) What role for photoperiod in the bud burst phenology of European beech. European Journal of Forest Research, 132, 1-8.

Vitasse $Y$ (2013) Ontogenic changes rather than difference in temperature cause understory trees to leaf out earlier. New phytologist, 198, 149-155.

Zohner CM, Benito BM, Svenning J-C, Renner SS (2016) Day length unlikely to constrain climate-driven shifts in leaf-out times of northern woody plants. Nature Climate Change, 6, 1120-1123.

Zohner, C. M., Mo, L., \& Renner, S. S. (2018). Global warming reduces leaf-out and flowering synchrony among individuals. eLife, 7, e40214. 
This study was supported support by the National Key Research and Development

463 Program of China (2017YFA06036001), the General program of National Nature 464 science foundation of China (No. 31770516) and the 111 Project (B18006) and 465 Fundamental Research Funds for the Central Universities (2018EYT05). Ivan A 466 Janssens and Josep Peñuelas acknowledge support from the European Research 467 Council through Synergy grant ERC-2013-SyG-610028 “IMBALANCE-P”. Ivan A 468 Janssens acknowledges support from the Research Council of the University of 469 Antwerp (Methusalem) and the "ECOPROPHET" project funded by BELSPO (Belgian 470 Science Policy Office; Contract SR/00/334). Constantin M. Zohner acknowledges 471 support from the ETH Zurich Postdoctoral Fellowship Program and the Crowther lab. 472 Our deepest gratitude goes to Dr. Christian Körner and the anonymous reviewers for 473 their careful work and thoughtful suggestions that have helped improve this paper 474 substantially. The authors gratefully acknowledge all members of the PEP725 project 475 for providing the phenological data. Y.H.F. and I.A.J. designed the research and drafted 476 the paper; Y.H.F. and X. Z performed the analysis and all authors contributed to the 477 interpretation of the results and to the text. 


\section{Supplementary Legends:}

480

481

482

483

484

485

486

487

488

489

490

491

492

493

494

495

496

497

498

499

500

501

Supplementary Table1. The mean GDD requirement of leaf-out in different daylength conditions, i.e. DLearly, short daylength effect, DLmid, average length in daylength and DLlate, long daylength effect, under same chilling accumulation conditions (case) for six tree species. Four chilling condition were studies, e.g. case 01 , chilling lowest; case02, chilling low, case03, chilling high and case04, chilling highest (see Methods for details). $\mathrm{n}$ indicates the number of trees.

Supplementary Table 2. The difference in mean GDD requirement of leaf-out between the daylength treatments, e.g. under short daylength: GDDshort DL; under optimal daylength: GDDavgDL; under long daylength: GDDlongDL) under the same chilling conditions in the low chilling accumulation group.

Supplementary figure 1. Distribution of the selected phenological sites.

Supplementary figure 2. (a) The climate of selected phenological sites. One circle indicates one site. (b) and (c) the annual temperature and precipitation across all selected sites.

Supplementary figure 3. Dependence of GDD requirement of leaf-out on daylength under constant chilling conditions for six tree species. Dependencies are shown for four different chilling intensities (see Methods). The GDD was calculated as daily sum of the daily temperature above 50C over the period from 1st September to the date of leafout

Supplementary figure 4. Dependence of GDD requirement of leaf-out on daylength under constant chilling conditions for six tree species. Dependencies are shown for four different chilling intensities (see Methods). The chilling was calculated as day 
when the daily temperature below $50 \mathrm{C}$ over the period from 1st September to the date of leaf-out.

\section{Supplementary figure 5. Dependence of GDD requirement of leaf-out on daylength} under constant chilling conditions for six tree species. Dependencies are shown for four different chilling intensities (see Methods). The chilling was calculated as day when the daily temperature below $70 \mathrm{C}$ over the period from 1st September to the date of leaf-out.

\section{Supplementary figure 6. Mean GDD requirement of leaf-out in the daylength} treatments (left panels) and under the same chilling (days) conditions (right panels) in the low chilling accumulation group. The numbers in the right panels are the mean chilling days in each of the three daylength regimes in the left panels (using the same colors). The GDD requirement was calculated as explained in Methods. Letters, i.e. a, $\mathrm{b}$ and $\mathrm{c}$, indicate statistically significant differences (at $P<0.001$ ).

Supplementary figure 7. Phylogenetic tree of European forest tree species and the family names were provided with different color. The figure was modified from study of Sardans et al., 2015. The species that selected in the present study were marked with pink boxes.

Supplementary figure 8. Changes in absolute and relative values of GDD requirement for spring leaf-out (across all chilling conditions) under one hour shorter (black) and longer (white) daylengths for each and all of the six studied species.

Supplementary figure 9. Dependence of GDD requirement of leaf-out on daylength under constant chilling conditions for six tree species. The GDD was calculated using a fixed length prior to leaf-out for each species at each site. Dependencies are shown for four different chilling intensities (see Methods). 
Supplementary Table 1. The mean GDD requirement of leaf-out in different daylength conditions, i.e. DLearly, short daylength effect, DLmid, average length in daylength and DLlate, long daylength effect, under same chilling accumulation conditions (case) for six tree species. Four chilling condition were studies, e.g. case01, chilling lowest; case02, chilling

530 low, case 03, chilling high and case04, chilling highest (see Methods for details). $\mathrm{n}$ indicates

531 the number of trees.

\begin{tabular}{ccccccccccc}
\hline \multirow{2}{*}{ Species (n) } & Chilling & DLearly & DLmid & DLlate & \multicolumn{2}{c}{ DLearly } & \multicolumn{2}{c}{ DLmid } & \multicolumn{2}{c}{ DLlate } \\
& conditions & (hours) & (hours) & (hours) & mean & std & mean & std & mean & std \\
\hline \multirow{2}{*}{ Aesculus } & case01 & 12.9 & 13.5 & 14.0 & 160.1 & 60.6 & 131.3 & 52.5 & 85.9 & 48.1 \\
hippocastanum & case02 & 13.1 & 13.6 & 14.1 & 138.9 & 48.9 & 107.5 & 39.3 & 74.9 & 36.3 \\
(2069) & case03 & 13.0 & 13.6 & 14.1 & 133.9 & 44.9 & 99.4 & 35.6 & 72.3 & 34.0 \\
& case04 & 13.2 & 13.7 & 14.1 & 133.0 & 49.8 & 81.6 & 35.7 & 66.4 & 34.1 \\
\hline \multirow{3}{*}{ Betula pendula } & case01 & 12.8 & 13.4 & 14.0 & 153.3 & 60.4 & 131 & 50.9 & 79.8 & 44.4 \\
(2052) & case02 & 13.1 & 13.7 & 14.1 & 134.0 & 48.9 & 77.0 & 32.4 & 60.8 & 29.4 \\
& case03 & 13.1 & 13.6 & 14.1 & 128.9 & 42.2 & 94.2 & 32.6 & 66.2 & 30.3 \\
& case04 & 13 & 13.6 & 14.1 & 132.6 & 45.3 & 103.4 & 35.7 & 68.9 & 32.2 \\
\hline \multirow{3}{*}{ Fagus sylvatica } & case01 & 13.3 & 13.8 & 14.2 & 182.4 & 77.9 & 146.8 & 63.2 & 113.9 & 55.2 \\
(1588) & case02 & 13.4 & 13.9 & 14.3 & 162.6 & 59.5 & 127.4 & 49.4 & 96.2 & 44.7 \\
& case03 & 13.5 & 13.9 & 14.3 & 159.8 & 54.5 & 122.0 & 43.8 & 92.5 & 42.3 \\
& case04 & 13.5 & 14 & 14.3 & 143.7 & 60.2 & 102.8 & 42.8 & 85.3 & 41.8 \\
\hline \multirow{3}{*}{ Fraxinus excelsior } & case01 & 13.7 & 14.2 & 14.6 & 229.0 & 87.1 & 199.4 & 70.4 & 164.5 & 62.9 \\
(1044) & case02 & 13.7 & 14.2 & 14.6 & 217.7 & 67.1 & 187.1 & 58.7 & 146.7 & 55.0 \\
& case03 & 13.8 & 14.3 & 14.6 & 214.6 & 65.9 & 179.6 & 55.5 & 144.7 & 53.7 \\
& case04 & 13.9 & 14.3 & 14.6 & 181.4 & 65.6 & 156.2 & 54.4 & 135.3 & 54.7 \\
\hline \multirow{2}{*}{ Qilia cordata } & case01 & 13.5 & 14.1 & 14.5 & 215.9 & 72.9 & 179.5 & 58 & 144.5 & 55.3 \\
(438) & case02 & 13.4 & 14.0 & 14.4 & 214.3 & 62.3 & 159.7 & 51.4 & 123.9 & 46.9 \\
& case03 & 13.5 & 14.0 & 14.4 & 195.4 & 55.3 & 153.2 & 46.2 & 122.8 & 46.5 \\
(1686) & case04 & 13.5 & 14.0 & 14.3 & 191.7 & 61.2 & 138.6 & 49.2 & 116.9 & 51.2 \\
\hline & case03 & 13.6 & 14.1 & 14.5 & 203.3 & 58.0 & 159.6 & 46.9 & 123.5 & 43.6 \\
& case04 & 13.7 & 14.2 & 14.5 & 201.5 & 62.1 & 163.7 & 48.7 & 124.3 & 46.8 \\
& & & 14.2 & 14.6 & 176.3 & 60.2 & 135.8 & 46.8 & 113.2 & 46 \\
\hline
\end{tabular}


533 Supplementary Table 2. The difference in mean GDD requirement of leaf-out between the 534 daylength treatments, e.g. under short daylength: GDDshort DL; under optimal daylength: 535 GDDavgDL; under long daylength: GDDlongDL) under the same chilling conditions in the 536 low chilling accumulation group.

\begin{tabular}{|c|c|c|c|c|c|c|}
\hline \multirow{2}{*}{ Species } & \multicolumn{3}{|c|}{ GDD shortDL vs. GDDavgDL } & \multicolumn{3}{|c|}{ GDD longDL vs. GDDavgDL } \\
\hline & $\mathrm{t}$ & $\mathrm{P}$ & $\mathrm{df}$ & $\mathrm{t}$ & $\mathrm{P}$ & df \\
\hline Aesculus hippocastanum & 32.986 & $<0.001$ & 1928 & -45.943 & $<0.001$ & 1928 \\
\hline Betula pendula & 33.118 & $<0.001$ & 970 & -32.853 & $<0.001$ & 970 \\
\hline Fagus sylvatica & 31.793 & $<0.001$ & 1491 & -36.568 & $<0.001$ & 1491 \\
\hline Fraxinus excelsior & 19.682 & $<0.001$ & 970 & -32.853 & $<0.001$ & 970 \\
\hline Quercus robur & 33.999 & $<0.001$ & 1569 & -40.378 & $<0.001$ & 1569 \\
\hline Tilia cordata & 22.646 & $<0.001$ & 396 & -18.238 & $<0.001$ & 396 \\
\hline
\end{tabular}


538 Supplementary figure 1. Distribution of the selected phenological sites.

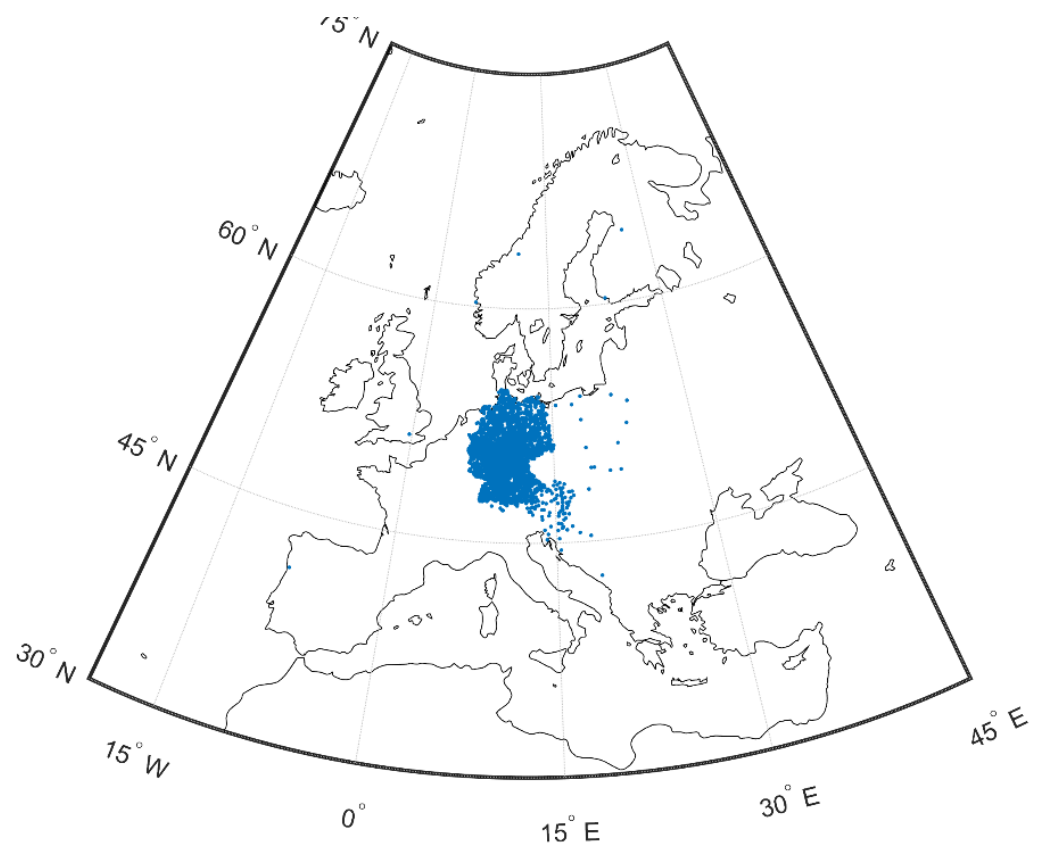


539 Supplementary figure 2. (a) The climate of selected phenological sites. One circle 540 indicates one site. (b) and (c) the annual temperature and precipitation across all 541 selected sites.

a

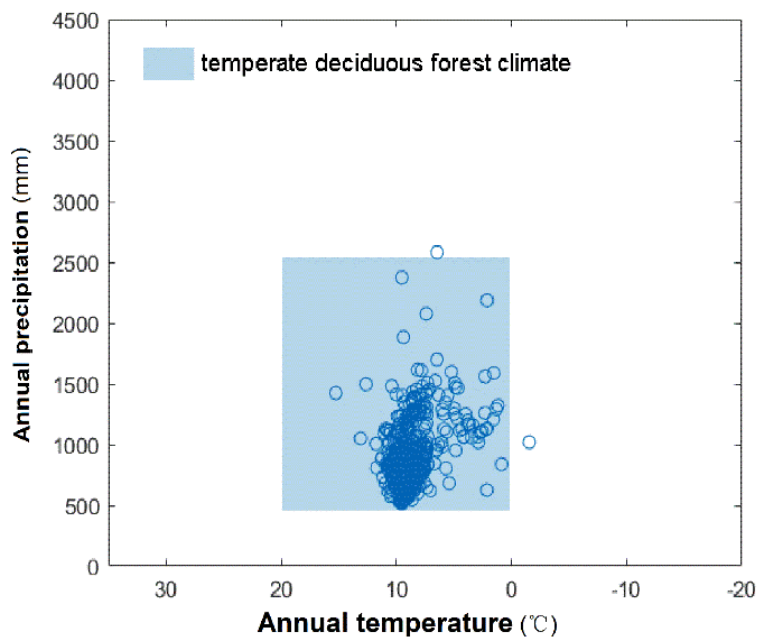

b
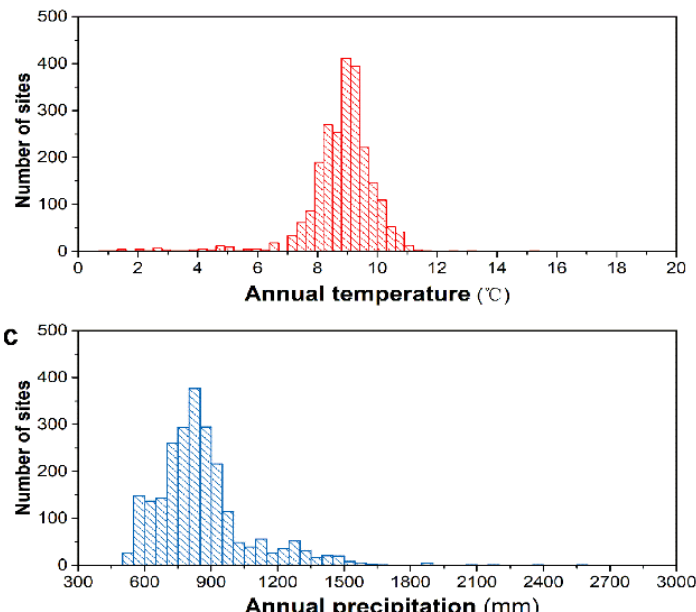
Supplementary figure 3. Dependence of GDD requirement of leaf-out on daylength under constant chilling conditions for six tree species. Dependencies are shown for four different chilling intensities (see Methods). The chilling was calculated as day when the daily temperature below $5^{0} \mathrm{C}$ over the period from 1 st September to the date 546 of leaf-out.
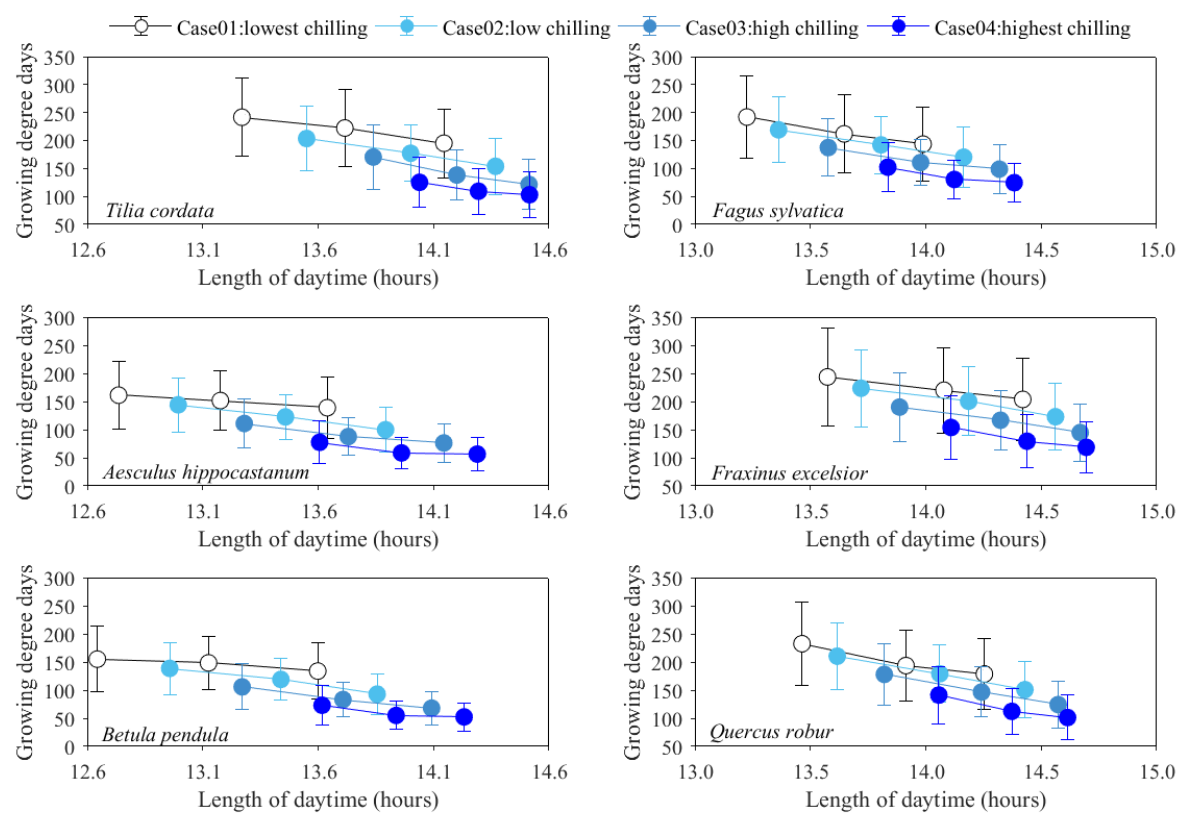
548 Supplementary figure 4. Dependence of GDD requirement of leaf-out on daylength under constant chilling conditions for six tree species. Dependencies are shown for four different chilling intensities (see Methods). The chilling was calculated as day when the daily temperature below $7^{0} \mathrm{C}$ over the period from 1 st September to the date of leaf-out.

553
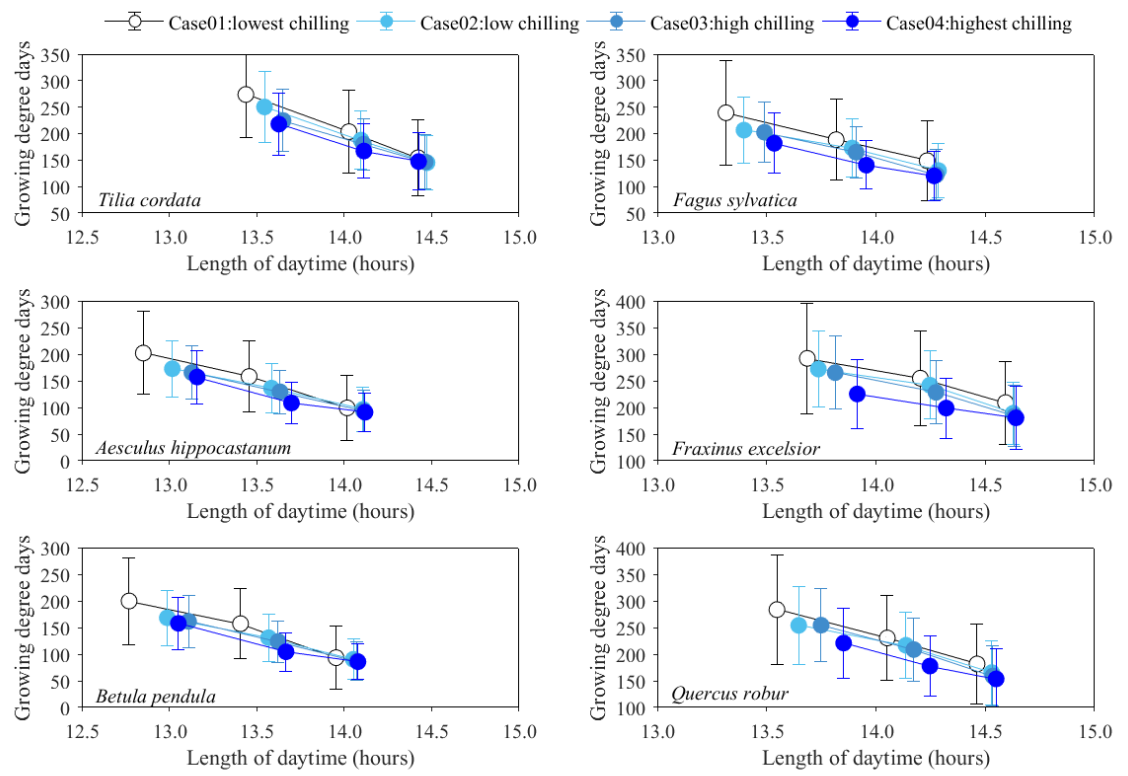
554 Supplementary figure 4. Dependence of GDD requirement of leaf-out on daylength 555 under constant chilling conditions for six tree species. Dependencies are shown for 556 four different chilling intensities (see Methods). The GDD was calculated as daily 557 sum of the daily temperature above $5^{0} \mathrm{C}$ over the period from 1 st December to the date 558 of leaf-out
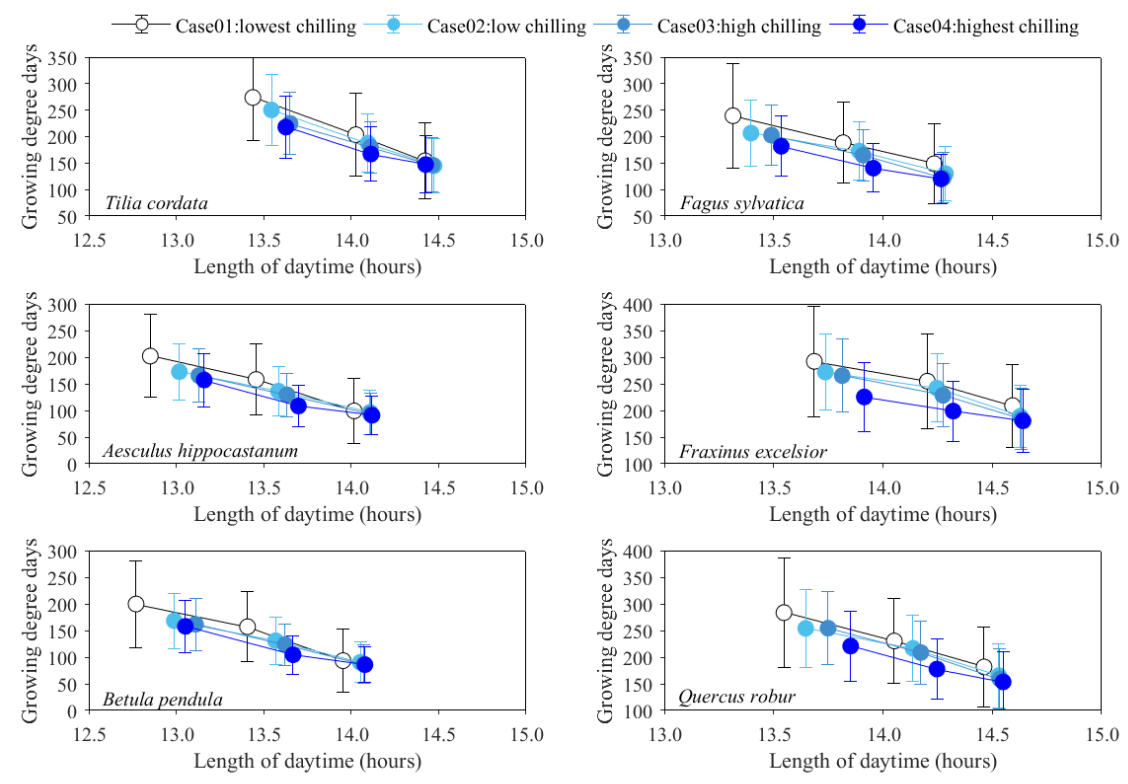
Supplementary figure 6. Mean GDD requirement of leaf-out in the daylength treatments accumulation group. The numbers in the right panels are the mean chilling days in each of the three daylength regimes in the left panels (using the same colors). The GDD requirement was calculated as explained in Methods. Letters, i.e. a, b and c, indicate statistically significant
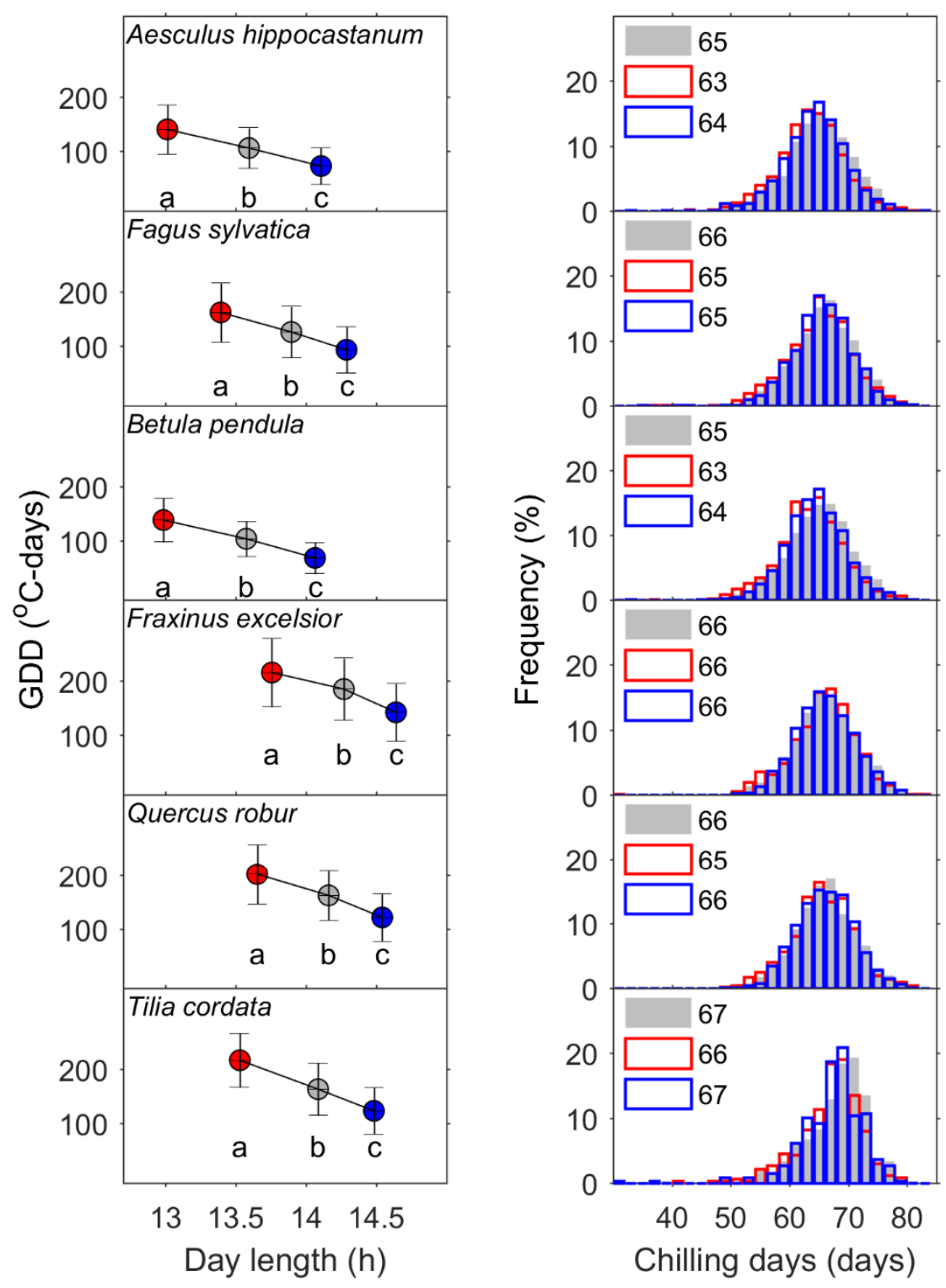
Supplementary figure 7. Phylogenetic tree of European forest tree species and the family names were provided with different color. The figure was modified from study of Sardans $e t$ al., 2015. The species that selected in the present study were marked with boxes.

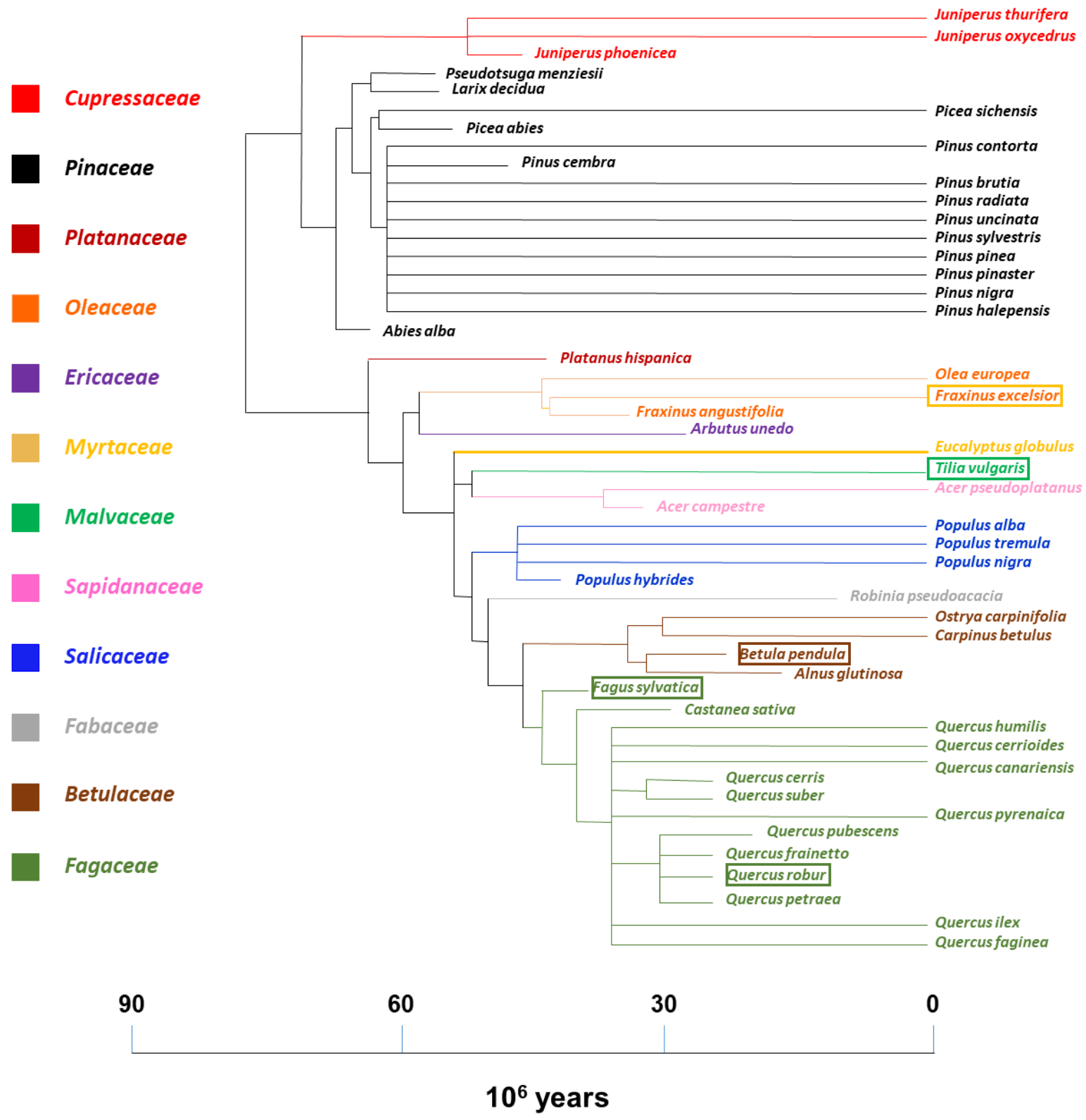


570 requirement for spring leaf-out (across all chilling conditions) under one hour shorter (black)

571 and longer (white) daylength for each and all of the six studied species.

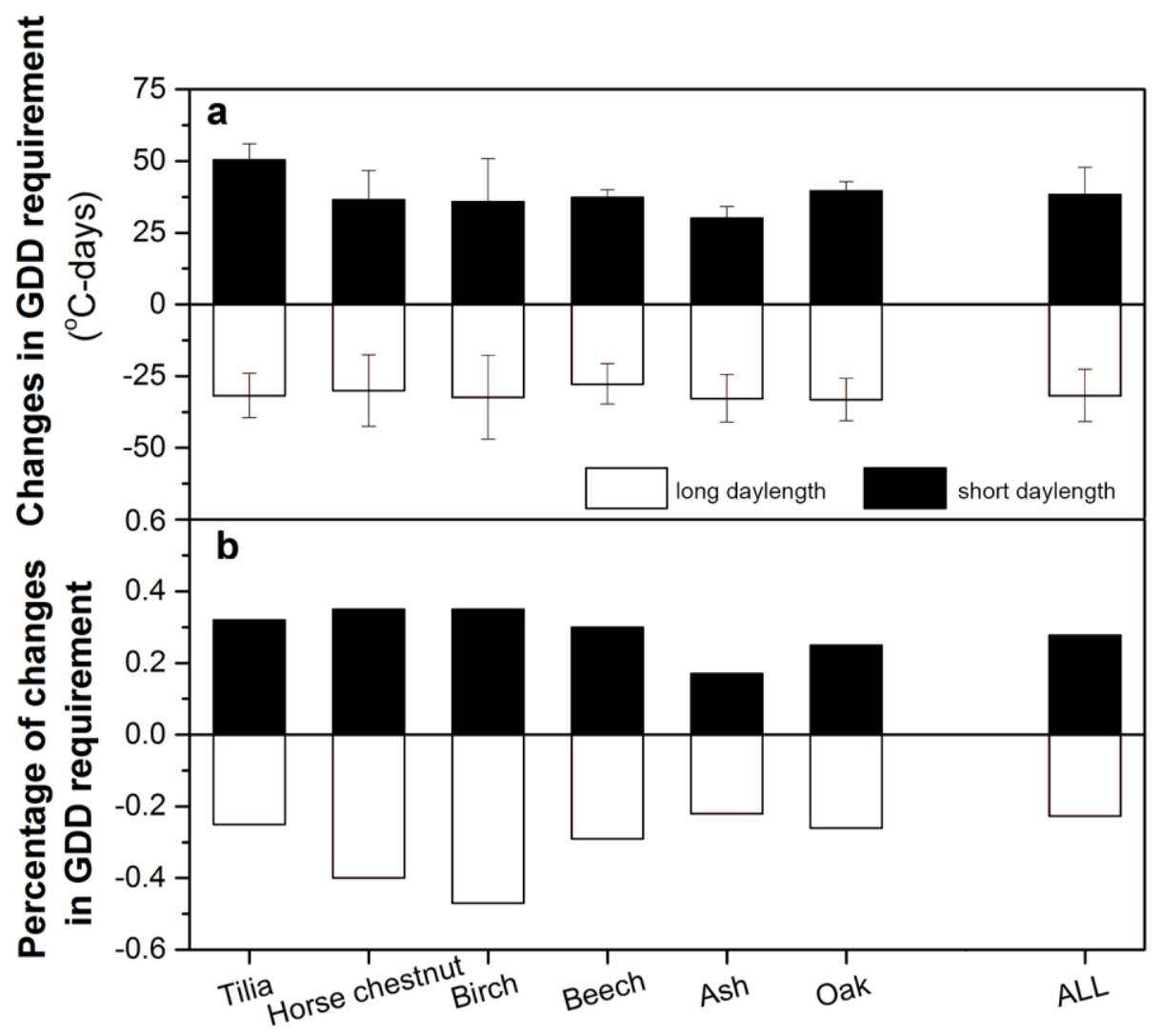


572 Supplementary figure 9. The distribution of normalized daylength (DL, in red) and chilling 573 (CD, in blue) sensitivity of GDD requirement for leaf-out for all study species. The histograms show the distribution across all sites and the mean sensitivities and standard deviations (in brackets) are provided. The GDD was calculated from the $1^{\text {st }}$ Jan to the date of leaf-out for each year of each species at each site.
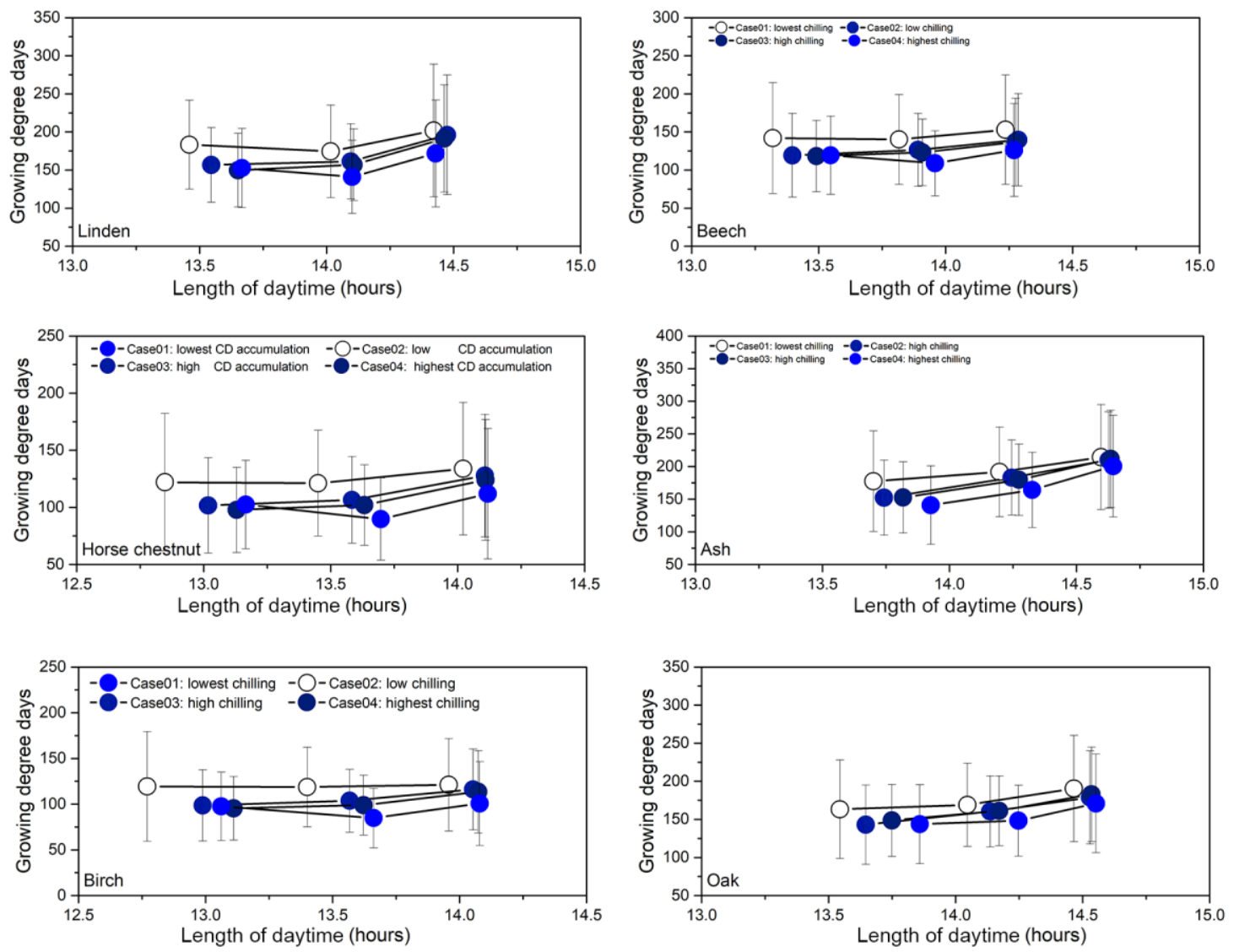